\title{
Tread Carefully: Managing Identities and Expectations in High-Tech Industry-Academia Collaborations
}

\author{
Els De Maeijer, Tom Van Hout, Mathieu Weggeman, and Ger Post
}

\author{
(6) will rapidly become accustomed to living in a constant \\ present and our understanding of who we are will emerge \\ through the context of the knowledges that are produced \\ within it.
}

Robert Hassan (2003)

Professor of Culture and Communication

\begin{abstract}
Industry-academia collaborations are in continual flux. The changing role of academics is reflected in the interaction between industry and academia. In this article, we examine how meetings as a genre are used to establish and alter the roles and identities of participants. First, interactional analysis shows that a meeting set-up revolving around academic presentations confirms an old role division between collaborators where academic contributions are vulnerable to undervaluation. Second, we found that so called "leading individuals" show critical discourse awareness that allows partners to reposition themselves in relation to each other. They use interactional strategies to create a joint purpose, empower participants to jointly realign, and motivate them to openly share progress. This results in a power shift where academics feel free to pursue their agendas. With this article, we try to understand how the choice of linguistic features shapes social and interpersonal relations in industry-academia collaborations by focusing on open innovation as a socially contingent process.
\end{abstract}

\section{Introduction}

Although it is widely recognized that collaborating with academia through open innovation is vital for the hightech industry - "companies that don't innovate die" (Chesbrough, 2006) - such collaborations also influence the nature of academic work. The potential commercialization of academic knowledge is a key driver for its funding (McCray, 2005) but exposes universities and knowledge centres to market forces, which curtails the traditionally long time horizon valued in academic research (Perkmann et al., 2011). Moreover, due to the increasingly short time-to-market, academics can no longer just be data suppliers or provide "research services" (Schmoch, 1999). Industry needs strategic innovation partners who facilitate a swift decision-making process based on certainties rather than risks. Deciding whether something can be done and which research steps should be taken next can no longer be an academic endeavour; research has to consider return on investment rather than just being an exercise in serendipitous experimentation. With the shift of attention to concrete problem solving and applicability for production comes a change in the network role (Erickson, 2005) of academics. Consequently, academics find themselves "betwixt and between" (Eksner \& Orellana, 2005) being scientists and managers.

We claim that such repositioning shapes the daily organization of joint innovation work between industry and academia. Academic and industrial partners inevitably have to meet up to discuss, align, and contest past achievements and future progress. It is thus "a process of joint spoken and written labor" (Urciuoli \& LaDousa, 2013), with language as the central medium of work (Koller, 2017), and meetings are ways of getting things done (Lehtinen \& Pälli, 2011) - of making innovation work. In line with previous research on meetings (e.g., Angouri \& Marra, 2011; Drew \& Heritage, 1992; Lehtinen \& Pälli, 2011; Nielsen, 2013), we consider such meetings to be embedded in the social and organizational context of a group or team, and in the wider social or 


\section{Tread Carefully: Managing Identities and Expectations in High-Tech Industry- Academia Collaborations Els De Maeijer, Tom Van Hout, Mathieu Weggeman, and Ger Post}

institutional order of the collaboration (Holmes \& Stubbe, 2003). (Project) meetings are mostly prepared face-to-face encounters (Lehtinen \& Pälli, 2011) at prearranged times and in set places such as academic or industrial campuses, industrial sites, and innovation hubs. Collaboration partners, who act as members of both the collaboration and the separate organizations to which they belong (Grant et al., 2005) bring context or discourse into those meetings. Under the current (western) phenomenon of acceleration (Brose, 2004), partners are tempted to fall back on instrumental thinking (Hassan, 2003). Instrumental thinking causes the "raw material of knowledge" to be only judged and processed through "abbreviated thinking", focusing on what knowledge is useful and useable in our own lives (Hassan, 2003). With such inflation of knowledge comes a transformation of universities into "skills centres" to maximize potential in the job market (McInnis, 2001; Schiller, 1999). Academic uncertainties can jeopardize the viability of industrial innovation projects and may be undesirable in industry-academia work.

Governmental research organizations promote industry-academia collaborations as examples of a healthy knowledge economy, but will these collaborations keep delivering under the current pressure of time? Uncertainty provides academia with a reason to exist; "not knowing things" acts as a catalyst for new experiments, further research, and fundamental knowledge creation. In this article, we examine to what extent industry-academia meetings are colonized by the instrumental logic of the high-tech industry and how these contextual elements are reconstituted within and by processes of interaction (Langley et al., 2013).

To find out more about the position of academia in industry-academia collaborations we need to find which discursive elements, relating to uncertainty and time pressure for example, are brought into the interactional process of knowledge creation. By looking at such interactional processes, we can learn how identities, roles, and relationships between open innovation partners are shaped in meetings.

The major research questions of this study are thus as follows:

\section{Which roles and identities do partners take in} industry-academia meetings?

2. How are those identities managed in interaction?

3. How does this process shape the knowledgecreation process?

\section{Methodology}

To answer the research questions, we use linguistic ethnography, which is the study of social practices through the lens of language and communication (Shaw et al., 2015). We draw on interactional analysis to unravel the meetings as examples of institutional interaction and connect the discursive patterns to the wider social context and structure of industry-academia open innovation.

With their specific rhetorical structures and distinctive lexico-grammatical features (Shaw et al., 2015), meetings constitute a specific genre, which makes them distinguishable from other events in a workplace context (Angouri \& Marra, 2011). Studying meetings can thus reveal which dedicated organizational routines are in place and who has experience with - and understanding of - those routines (Drew \& Heritage, 1992). Looking at the formal and sequential properties of talk - for example, word selection, topic selection, and ordering of sequences - allows us to make claims about the inferential order of interaction, such as the asymmetry in distribution of actors' rights and obligations (Drew \& Heritage, 1992) within the genre of the meeting.

We used three kinds of data, which is typical of ethnographic research, which were gathered between February 2015 and September 2017 by the first author. First, we audio-recorded project meetings in three collaborative industrial-academic settings all serving the high-tech industry (mostly the semi-conductor field). For this article, we focus on two projects, anonymized as "Phi" and "Omicron". Both projects were set up with governmental support for fundamental research in physics and its commercialization, which means that partners are required to meet to at least once a year to evaluate the progress made in the project. Furthermore, projects are required to invite (potential) industrial users of the developing technologies to the meetings. In this setting, we gathered roughly 20 hours of meeting audio. In the Phi project, we also audio-recorded a bilateral work meeting between two of the three main partners. In the Omicron project, we extended our data to an over-arching program meeting in which Omicron was reviewed among all the other projects in the program. Second, we interviewed representative individuals of the partners involved in the projects (in semi-structured interviews), some previous employees, and the governmental intermediary of Omicron (and previously Phi) to gather a more complete understanding of the context of the collaborations. Furthermore, we had several informal conversations with various members of staff in the partnership, equally 


\section{Tread Carefully: Managing Identities and Expectations in High-Tech Industry- Academia Collaborations Els De Maeijer, Tom Van Hout, Mathieu Weggeman, and Ger Post}

divided between both projects. The non-technical background of the first author made her into the so-called "acceptable incompetent" ethnographer (Lofland \& Lofland, 1995) allowing for more incisive questions to reveal participants true beliefs and values. Finally, we added field notes taken during the non-participant direct observations, reflective notes on informal conversations, and secondary data such as emails, meeting agendas, and supporting PowerPoint presentations to create a "detailed tapestry" (Briguglio, 2016) of themes and patterns, which were cross-validated and triangulated in more follow-up interviews/feedback sessions with participants. The third partnership, extensively studied previously (De Maeijer, Van Hout, Weggeman, \& Post, 2017), serves as a comparison by way of extension (Czarniawski, 2012) and validation. The research methodology is summarized in Figure 1.

Utterances were coded not only to guarantee grounding of the theoretical interpretation in linguistic empirical evidence but also to allow new phenomena to emerge and thereby sensitize researchers to concepts that previously have been excluded from the framework of existing open innovation theories. Linguistic ethnography can thus describe the discourse of these industry-academia collaborations with its beliefs, values, and motivations, and it can connect these descriptions to interactional patterns, thereby challenging or adding nuance to some of the presuppositions (Urban \& Koh, 2013) about such collaborations.

In this article, we try to reach beyond the description of the processes as they happen (Langley et al., 2013) and to understand "how one's choice of linguistic features shapes social and interpersonal relations in communicative events" (Weninger \& Kan, 2013). With the current stress on the instrumental validation of knowledge associated with an industrial paradigm, we can expect that these choices will shed light on how identities are managed in conversation and how they are reflected in the (presumably unequal) distribution of power (Koller, 2017).

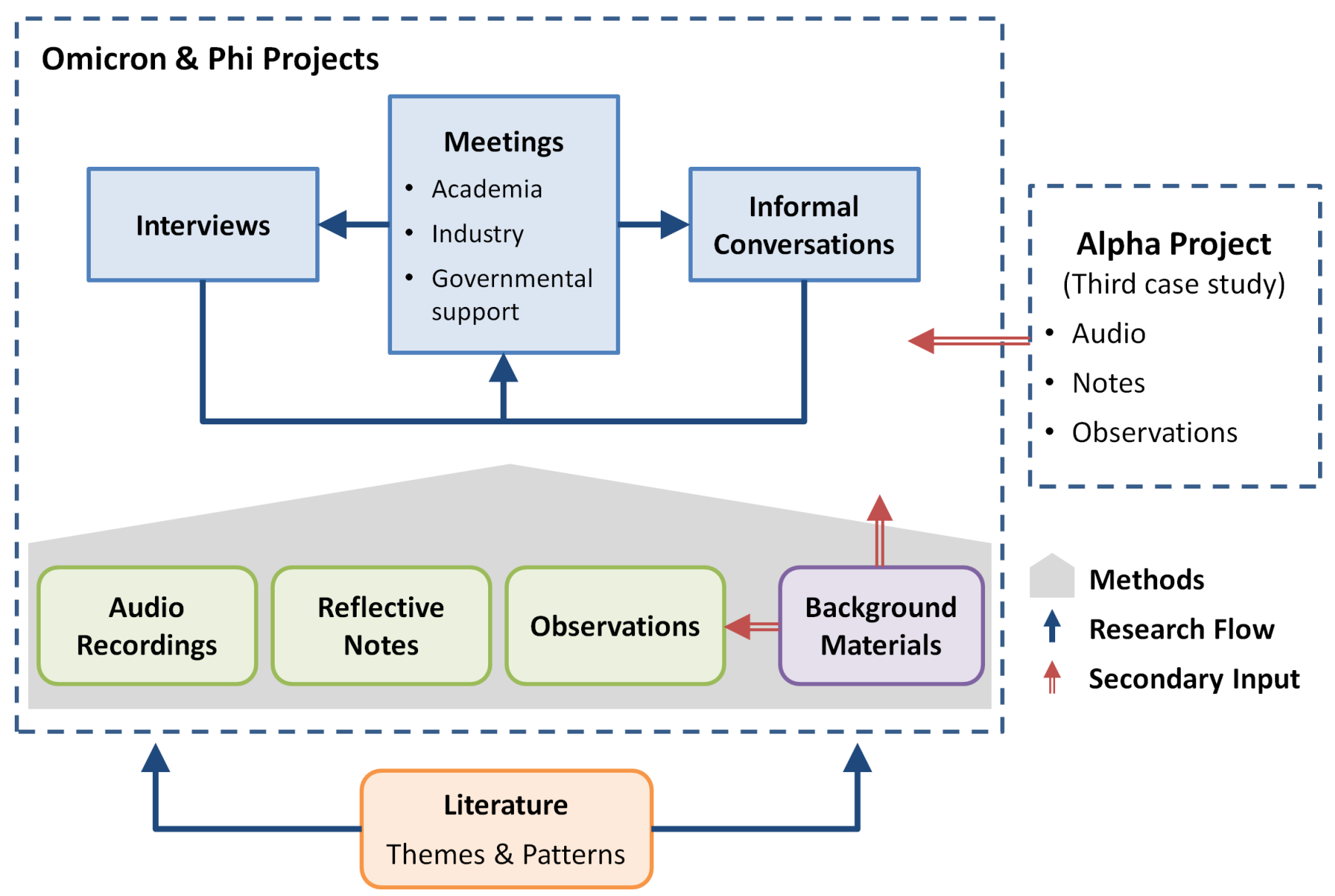

Figure 1. Research set-up showing sources and methods used for data gathering 


\section{Tread Carefully: Managing Identities and Expectations in High-Tech Industry- Academia Collaborations Els De Maeijer, Tom Van Hout, Mathieu Weggeman, and Ger Post}

\section{Analytical Framework}

We propose to approach open innovation as a social process where openness is an observable linguistic practice rather than a collection of intentions and attitudes (Potter \& Wetherell, 1987). This approach is in line with Costas and Grey's (2014) approach to secrecy (as opposed to transparency); in the same way as people are engaged in the practice of secrecy to keep something a secret (Costas \& Grey, 2014), people are actively engaged in "being open". Secrecy is related to (group) identity and power (Moore, 1962), as knowing or not knowing things puts people in a group of insiders or outsiders. However, literature on open innovation takes an informational approach (Dufresne \& Offstein, 2008) to openness as it considers it as the preparedness to share information with others and the preparedness to get information from others, with the assumption that such information is of high tactical or strategic value (Dufresne \& Offstein, 2008). With the value of information comes, perhaps ironically, attention to how, in such an open climate, innovations can be protected, on appropriability, intellectual property rights, and patenting. Other research focuses on which conditions on the front side of open innovation stimulate an "effective knowledge sharing process". Simard and West (2006), for example, have paid considerable attention to the role of relationships or ties between open innovation partners. For instance, they distinguish between wide and deep ties and relate these ties to trust levels and thus openness in the collaboration. They argue that the heterogeneity of partners creates room for different perspectives and more "out of the box" solutions to problems, but also that sustained collaboration over time creates more trust and reduces the risks in a collaboration. This idea of a "pay-off between trust and novelty and safety and flexibility" (Gargiulo \& Benassi, 2000) has been further elaborated on by research on how employee diversity can affect openness to external sources (Bogers, Foss, \& Lyngsie, 2018). Such research assumes that, when the right conditions are created at the front side of collaborations with sufficient real-life interaction (Agrawal \& Cockburn, 2003), the right personal networks (MacDonald \& Piekkari, 2005), and suitable legal security, an open flow of knowledge is established.

Our approach to openness does not dismiss the organizational dilemmas and strategies described above, but considers them given discourse. Focusing on the conditions, intentions, and attitudes as key factors for successful open innovation outcomes goes at the expense of paying attention to how innovation happens between these heterogeneous partners. There is an overwhelming emphasis in most management research on the importance of outcomes (Langley et al., 2013). Research on open innovation is no different, with the exception of a few studies such as Van Oortmerssen's (2014) study on the effect of turn-taking in collaborations or the recent attention that intermediaries have received for their role in bridging the cognitive, geographic and social distance between industrials and academics (e.g., Villani et al., 2016) and in establishing a creative climate with room for new ideas (Agogué et al., 2013). Although these studies offer a valuable glimpse on the interactional aspects of collaborations, there is very little room for the processes of collaboration that happen right under our nose, for the patterns in the interaction, what they signal nor how such patterns shape the future of industry-academia work. In that respect, we would like to refer to earlier research (De Maeijer et al., 2017) where we connected openness to the use of an interactional strategy called facework (Goffman, 1967). Due to the liminal or in-between position of partners (being neither academics nor industrials), collaborating parties fear to be granted attributes that do not match their preferred network role (old or new one) and thus also refrain from putting their partners in a position where they have to confess on their ability and willingness or lack of it to perform certain activities within a limited time-frame. This dynamic, which is "keeping face" (Spencer-Oaty, 2009), is an integral part of everyday interaction aimed at not damaging individuals perceived self-image. With liminality comes uncertainty about how others want to be seen in their capabilities, values, and beliefs. To prevent face-threats, research purposes, activities, and deliverables are often quietly assumed rather than openly debated. This, in turn, makes expectation management in the collaborations harder, and this lack of transparency can kill the trust between the parties. The focus on the interactional process adds empirical evidence to Erikson (2005) who concluded that trust built on previous interaction may be reduced through changes in network roles (Simard \& West, 2006).

The focus on the process of openness hence shows that the reality of open innovation is a result of context continually being reconstituted within and by processes of interaction over time and that actors, environments, and organizations are all in constant and mutually interacting flux (Langley et al., 2013). Hence, with this article, we contribute to distinguishing the myths of open innovation, constructed in managerial talk, governmental policies, and regional marketing strategies from the reality of open innovation collaborations, and more specifically of the role of academia in the latter. 


\section{Tread Carefully: Managing Identities and Expectations in High-Tech Industry- Academia Collaborations Els De Maeijer, Tom Van Hout, Mathieu Weggeman, and Ger Post}

\section{Analysis of the Interaction}

Investigating meetings as platforms where open innovation "works", we focus on two aspects that help participants to identify the roles and identities that are taken in the collaboration and to act accordingly to the expectations that these identities imply. The very fact that participants gather in "formal" meetings helps to create certainty about what expectations to have of each other. First, the recognition of genres, such as meetings and presentations, supports sense-making as it clarifies who is in charge, how to interpret certain behaviour, and what positions, and accordingly what actions, should be taken in the meeting and hence in the project itself. Second, we show how participants rely on "leading" individuals to further tease out what roles and identities are and should be taken up during the meeting and which interactional step is the most "appropriate" one to take. Figure 2 provides a basic overview of the organization of the meetings and which strategies are applied. We will relate genre recognition (based on organizational features in the left column) and the observed interactional interventions (in the right column) to management and leadership discourse. Finally, we will explain how mixing both discourses can benefit the knowledge-creation process.

\section{The Meeting as a Management Genre}

The interaction between industry and academia in both the Phi and Omicron projects is organized in work and in user meetings. It is the sheer recognition of the meeting as a genre by the participants that provides safe boundaries of what can be expected to happen. By genre recognition, we mean that participants recognize the rhetorical structure and the distinctive lexico-grammatical features contingent on the social norms and embedded practices of recurring situations (Lehtinen \&

\section{Organization of the Meetings}

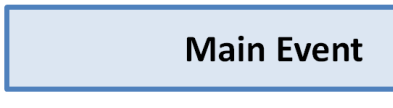

- Set-up with presentations
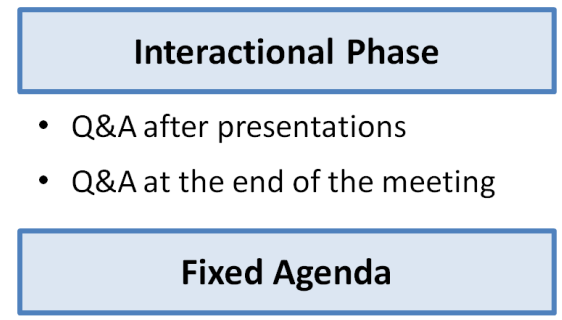

- Meticulous time management

- Room for discussion on technological uncertainty

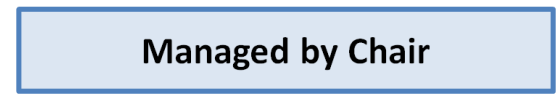

- Grant or take away speaking rights

\section{Interactional Strategies}
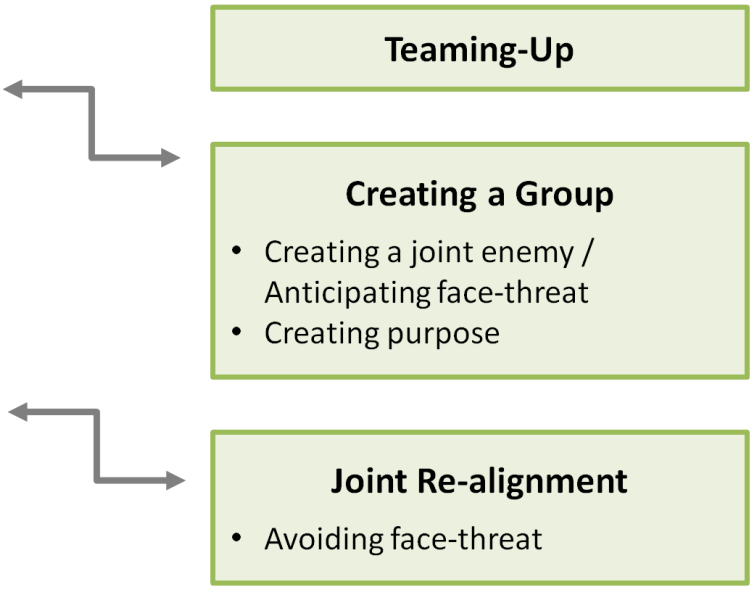

Giving Constructive Feedback

\section{Reducing Hierarchical Distance}

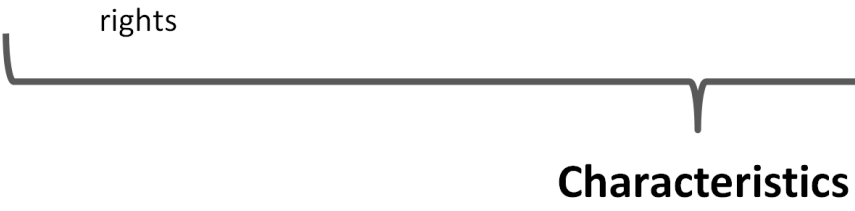

Industrical instrumentalism - Acceptance of uncertainty - Emancipation of academia

Figure 2. Summary of the organization of the meetings between industrials and academics and the interactional strategies they use 


\section{Tread Carefully: Managing Identities and Expectations in High-Tech Industry- Academia Collaborations Els De Maeijer, Tom Van Hout, Mathieu Weggeman, and Ger Post}

Pälli, 2011). This knowledge is implicit as participants comply with the norms, standards, and routines of meetings without having to explicate the meaning of the genre. So, when participants have a project meeting scheduled, they know for example that, in contrast to a "normal" day at the office or in the lab, they will be seated in a room with delegates from external organizations and that the interaction will be regulated by a chair. Those assumptions are based on the participants' knowledge of and experience with what a meeting constitutes. When the project-leader sends out the agenda of the meeting via email, assumptions about who will be participating, role division, and allocated speaking turns (Angouri \& Marra, 2011) can already become confirmed. The agendas indicate who should be actively involved in the meeting (i.e., who will be doing most of the talking), when, and for how long (Figure 3). The agendas of Phi and particularly of Omicron show that meticulous time management is expected of the participants (Figure 4).

Even the actual gathering of participants, which Kunda (1992) calls the "transitional phase during which participants gather and jointly shift from routine to ritual" is taken up in the agenda of the program meeting as a dedicated timeslot for "Coffee", which gives the chair the procedural back-up to open the meeting. Such a formal approach to the meeting fits a management discourse reflecting the importance of "the smooth running of the business" (Norlyk, 2012). The chair manages

\section{Phi Project - Agenda}

Subtitle [description of scientific technique for commercialization]

Date \& location [University building]

Time 10:00 - 13:30 with lunch

Building and room number

10:00 Introduction and Welcome

[Project leader] University

10:15 Project Planning, Status and Outlook

[Project leader \& representative institute],

University \& Research Centre

10:30 [Technical Subject 1]

(15 min. talk + 15 min. discussion)

[PhD-student], University

11:00 [Technical Subject 2]

(15 min. talk + 15 min. discussion)

[Researcher], Research Centre

11:30 Title

(15 min. talk +15 min. discussion)

[Researcher], Research Centre

12:00 Feedback from User Committee

Discussion \& Lunch

$12: 30$

End

\section{Notes}

- The agenda of the meeting is sent out to invitees in advance.

- The meeting is chaired by the project leader of the university and takes place at the university itself. The project leader opens the meeting. The Phi meeting analyzed in this study was opened by the industrial representative as it is hosted by the company.

- The name of the person presenting would be listed in place of text in square brackets [ ], followed by their organization name.

- On the agenda, Q\&A is strictly organized after each "main event". In reality, the speaker is interrupted for questions during their talk. Q\&A and the feedback of the user committee are not distinguishable as separate activities.

Figure 3. Annotated example agenda from a Phi program meeting 


\section{Tread Carefully: Managing Identities and Expectations in High-Tech Industry- Academia Collaborations Els De Maeijer, Tom Van Hout, Mathieu Weggeman, and Ger Post}

\begin{tabular}{|c|c|c|c|}
\hline 4 & A & B & C \\
\hline 1 & Agenda Item & Speaker & Time Slot \\
\hline 2 & 2-minute overview of project $A 1$ & Program Manager & $11.00-11.02$ \\
\hline 3 & Ideas and realizations of ---------- & Scientist & $11.03-11.30$ \\
\hline 4 & & & \\
\hline 5 & 2-minute overview of project $A 2$ & Program Manager & $11.30-11.32$ \\
\hline 6 & Use of the ---------- & Scientist A/Scientist B & $11.32-11.45$ \\
\hline 7 & Ideas and realizations of ---------- & Program Manager/Scientist C & $11.45-12.00$ \\
\hline 8 & & & \\
\hline 9 & 2-minute overview of project $A 3$ & External Scientist & $12.00-12.02$ \\
\hline 10 & & & \\
\hline $\begin{array}{l}11 \\
12\end{array}$ & & & \\
\hline
\end{tabular}

Figure 4. Example partial agenda from an Omicron program meeting showing very detailed timing and topics. The full agenda was sent out as an Excel file with 26 items with time slots ranging from 2 to 30 minutes.

the meeting and hence is held responsible for its planning, structure, and productivity. The focus on procedures brings efficiency. Such an approach is appreciated by the industrial partners who frequently apply a management discourse of timelines and deadlines (De Maeijer et al., 2017) setting the norms for the appropriate timing for action (Garud et al., 2014).

\section{Presentations}

In Phi and Omicron, about $70 \%$ of the items on the agenda are given to academics. In fact, most of the "the main event" (Kunda, 1992), or the actual meeting, is made up of separate "talks" by academic researchers (often $\mathrm{PhD}$ students) who are given the opportunity to show what they have achieved up to that point. Although the agendas never use the word "presentation", we can clearly distinguish the activity type of a presentation; speakers' turns are about 12 to 20 minutes of uninterrupted talk and are supported with PowerPoint slides. Although it is perhaps counterintuitive that this specific organization of "speaking turns" provides the listener rather than the speaker with power, observations of the meetings teach us that this unequal distribution of speaking rights (or obligations) has perhaps unintended and status determining implications for the academics in the meeting:

"The meeting was bad because there was no engagement and passion in the presentations and the quality of the stories... well, there was just nothing new. Also, no vision was put down, nothing like 'this is what we are going to do in the next coming months'." (Industrial CEO and user at Omicron program meeting; emphasis added)

First of all, giving a presentation implies that you have something to show, something of value, something new, or something that whoever is listening did not know already (Merriam Webster, 2018). Second, this implies that, as a presenter, you expect the listener to have an opinion. The listener has the privilege to evaluate, vote on, or judge the presentation. On the agenda, we can see that this takes shape in Q\&A sessions by fellow academics, industrial fellow project members, and industrial users. Kunda (1992) calls this the interactive phase "in which different individuals engage and even resist the speaker". This interactive phase can be organized at the end of a meeting, or take place straight after each short presentation (see the Phi agenda example in Figure 3). In this case, the meeting is actually made up of cycles of main events and interactive phases. Even when the agenda offers no explicit space for Q\&A (as we have seen in the third case studied), presenters have to be on guard for reactions from the public. Sometimes a reaction is explicitly asked for by the chair ("Are there any more questions?") or implicitly through the use of the discourse marker "Ok", silence, and intonation to mark the end of a presentation, simultaneously serving as cue for applause, critique, or questions. Previous experience and genre knowledge provide both presenters and public with knowledge to infer what is expected of them in this interaction phase. However, this cycle of 


\section{Tread Carefully: Managing Identities and Expectations in High-Tech Industry- Academia Collaborations Els De Maeijer, Tom Van Hout, Mathieu Weggeman, and Ger Post}

phases also puts the presenter under pressure to bring across something of value within their allocated speaking turn. The presenter furthermore knows that speaking rights can be taken away by the chair when a presentation goes overtime. Moreover, under perceived time pressure, the chair can decide to cancel a presentation when the news value is assumed to be low:

\begin{abstract}
"So let's have a look at the presentations actually, because the presentation that Jan is going to give, for the people that are interested in it are the academic guys, but they've already seen it. So Jan's presentation is not essential for seeing the progress of this project. So, we skip that one. You are allowed to do it next time." (Project leader Omicron at user meeting Omicron; emphasis added)
\end{abstract}

Presenters thus always find themselves in a vulnerable position as it is up to others to decide if the information is valuable enough for the presenter to make it to the stage. When the presenter does present here, he makes extra efforts to make the public see the value of his message or to help the public pick out the most valuable takeaways. He does so by adding discourse markers ("So, what is interesting here, is that you can see this as an example of...") and by teaming-up (Lerner, 1987):

"So that is what we need to figure out. So Hank [the chair and program leader] and I got the idea to add this new item to the machine. And once we have that we have maybe we do the measuring and then we can do the analysis." (Researcher Omicron at Omicron program meeting; emphasis added)

In teaming up, the researcher uses the authority of the program leader to back up the value of his proposal. When a senior researcher in the public subsequently starts asking the presenter questions, inferring doubt about the correctness of the research, the program leader jumps in: "So what you are saying is that...". He paraphrases the senior researcher, eliminating the question and then adds some clarification to the presentation. The presenter, with his initial referral to the program leader ("Hank and I got the idea..."), prepared this opportunity for the program leader to offer him additional support during Q\&A. Presenter and program leader, both academics, stand united, which adds weight to the presentation. Of course, this is an add-on for the program leader, as a better valuation rubs off on him as it is his responsibility as a chair to enable an interesting meeting. In Phi, the same dynamics happen between supervisors and their PhD students as it is of course in the interest of the supervisor that the work of their PhD student is valued by the public.

\section{Implication}

The routines, or "knowable" organizational activities (Lehtinen \& Pälli, 2011) described above shape the discourse of these open innovation meetings. The set-up of the meeting with academic presentations suits the "traditional" view of academia as a service or data provider: academics are invited to the stage to show what it is that "they" can do for "us" as efficiently as possible. It is symptomatic of an industry-academia relation where the university or research centre mainly provides research services and where contractual obligations determine what the supplier should deliver (Schmoch, 1999). It seems strange though that such a formal agenda mainly constituted of presentations is always set up by the academic project leader or by the governmental intermediary. However, old habits die hard; if meetings were always organized in this way, it can be convenient and self-evident to keep doing what has always been done. Habits are grounded in history, which is, in turn, an important part of identity. The meeting set-up allows academia to "act in character" (Goia, 2013) and carry out those actions that are grounded in the old role division. This brings us to a second explanation for this set-up; it is custom for academia to take up a critical role. "In academia you always look at what is wrong, that's how science becomes better", one of the interviewees remarked. So, with this meeting set-up academics act upon their core values (Goia, 2013) and do what they know best; trying to prove the solidity of scientific research by enabling questions and critique. However, in such an interdisciplinary, interorganizational setting, where academic value is measured by its commercial perspective, this set-up puts academics in a position where the value can be yanked out from underneath their contribution to the collaboration.

\section{Towards a Partnership}

There is also a different dynamic at play that allows a transformation of identity of the academic partner or at least accommodates a stage of liminality. Participants use the institutional characteristics of meetings as an opportunity to manage how they want to be perceived in relationship to one another, in other words, to manage their identities. We argue that the ability to use these characteristics requires a sense of critical discourse. By this, we mean that the speaker not only recognizes certain linguistic features as characteristics of the discourse, including relations of unequal power 


\section{Tread Carefully: Managing Identities and Expectations in High-Tech Industry- Academia Collaborations Els De Maeijer, Tom Van Hout, Mathieu Weggeman, and Ger Post}

(Koller, 2017), but also knows how to use those linguistic features to mold the social relationship of the collaboration. We will discuss three interactional patterns providing purpose, joint alignment, and motivation that occur during the meetings and explain how and why these patterns further shape the identity of academic partners by giving them a sense of empowerment.

\section{Providing purpose}

We have already discussed the relative power of the chair when we talked about teaming-up among academics in the previous section. Here, we describe how the chair uses their role to play with the relative power of industry and academia in the meeting. We focus on the opening sequence of a Phi user meeting hosted by Rick, the industrial partner, at the home industrial site:

Rick: "First of all, wishing you welcome here. And, you already found the refreshments in the back. Okay... well thank you... [1.2 seconds pause]... ehm, so I want to... eh, to kick off... eh, this meeting... [1.4 seconds pause]... ehm, and Bernard and, eh, Jeff... eh, asked me to, to also give a short, sort of introduction, into, as to why our company again was interested in this... eh, so why are we doing this together."

Although we may expect the academic project manager to be the chair of the meeting, Rick takes the pivotal role (Levinson, 1992) of opening the meeting - a position that grants him with fundamental rights to the floor (Nielsen, 2010). In his hesitation (pauses and "ehms"), and by him adding that he was asked to do so, he shows awareness about the unconventionality of his role at this particular moment. Rick tries to avoid the impression that he is out of place taking the lead and thereby recognizes his academic partner. Rick goes on to remind the attendees about the purpose of the collaboration:

Rick: "And the reason obviously comes from our customers in the semi-conductor industry. We have two... road maps towards serving our business unit electronics customers. So that is our prime direction, the second direction is... suppose this won't work, what do we do then?"

Explicating the "why" is an important way to haul in the academic party as a partner, without whom the goals cannot be met. Expressing (ethical) commitment and the importance of making a difference in society con- tributes to building a relationship with internal and external stakeholders (Norlyk, 2012). Although perhaps it is too far-fetched to label Rick's introduction as showing ethical commitment, he does show how the group (internally the industrial partner and externally the research institutes) can make a difference:

Rick: "Currently this technique in semi-conductor, even in research labs, is hardly ever conducted. The main reason for that is that the technique is difficult and time-consuming, so if we can alleviate that and make it easy and quick then it becomes a much more viable technique to be used in practice in the semi-conductor industry as a more routine tool rather than a specialized tool."

Rick takes leadership as he identifies and communicates the corporate and organizational purpose (Norlyk, 2012). This creates a group of the attendees, as he implicitly says that making this possible is the responsibility of the project team. However, he uses reported speech rather than paraphrasing what it is that the customer wants, thereby distancing himself somewhat from the purpose of the collaboration. By clearly stating that it is the customer's wish, he avoids being seen as laying down the law himself:

Rick: "So the data has to adhere to certain requirements. But it is something that they say: 'Well, actually, we are not that interested in this technology per se. It would for us already be sufficient if we have the other method available."'

He is not the one who set up the criteria and created the difficulties for academic participants:

Rick: "We need to feed the semiconductor industry with a constant flow of innovations and while still of course keeping this end goal in mind. So that also means that we [the company] will collaborate with you guys more directly than we normally do. [1.4 seconds pause] for instance... eh, the institute is already feeling the pain from that you know with me telling Chass [a PhD student] not to use a certain toolbox [laughter] because it [laughter] makes it more [laughter] difficult for [laughter] me to change it in our commercial software, but that is, yeah, that is the way we really want to work now eh... together."

Rick expresses his understanding for things not being ideal, but reminds everyone that it is "the way we really 


\section{Tread Carefully: Managing Identities and Expectations in High-Tech Industry- Academia Collaborations Els De Maeijer, Tom Van Hout, Mathieu Weggeman, and Ger Post}

want to work now". Note the fact that Rick adds "togeth$e r$ " at the end of the sentence (while grammatically we would have expected this word before "now"), and it is as if, by adding this, he wants to make sure that everybody feels included. His apologetic tone, marked by the interjected laughs and him distancing himself from the customer's demands, compensates for the elements of strong definitory power held by a leadership discourse (Norlyk, 2012). He anticipates the possibility of resistance or face-threat and gives voice to the power relation in place ("you know with me telling Chass not to use a certain toolbox"), thereby recognizing the possibility that academia may find it hard to collaborate like that. It gives recognition to academia as a partner rather than a service provider in the sense that a partner has equal rights to agree with or protest against a certain way of working.

\section{Joint realignment}

Having examined the openings of the meetings, we presumed that the closings of the meeting provided equally important opportunities to recapitulate the value and purpose of the collaboration. Such "morals" or "lessons" (Schegloff \& Sacks, 1973) frequently appear in closing sections and could provide the attendees with a sense of satisfaction or purpose. However, all of the observed "closings" of meetings went rather abruptly with the chair thanking attendees for their presence. Instead, we observed a frequent reassurance and realignment of the goals and direction of the project throughout the meetings of Phi. During, but also outside Q\&A, participants are allowed plenty of time for exploration and "if-then" thought experiments. Users are explicitly given the opportunity to explore further technical possibilities ("I think even further, this might also help you to find the other measurement.") and project members think out loud about alternatives for currently presented techniques ("So, let's say that this is the case, would it be possible to find another way to get the same result?') or consider why there might be a lack of solutions ("Oh, so I guess that this is the reason that you are not able to get rid of the defect."). Based on the discussion and following this kind of input, participants jointly decide if a different path should be taken in the research project ("This is interesting, so we could also consider to go with that. This could be a winner!'), or try to clarify the initial path taken:

"I have another question, because, if we do it that way, we need some software, but I'm kind of missing that here, and I am not so sure. I thought that would be a part of this project, so I'm not sure who

\begin{abstract}
is going to tackle that problem. Because I entirely agree, at the end of the day, that's the only way we will get to our goal." (Director of Research \& Technology - responsible for innovation strategies at the industrial partner of Phi - at user meeting Phi)
\end{abstract}

This form of realignment stands in sharp contrast to what we have witnessed in the third case where realignment was the result of a one-sided expression of control by the industrials in the meetings. Questions about responsibility and tasks were more often than not met with silence from the academic partner and led to frustration about the dominant style of the industrials (De Maeijer et al., 2017). Here, however, such points are often well received ("I do - it's a very good point. It was very implicitly originally in what we've discussed and it's sort of not explicit anymore.") and representing project members jointly realign by stipulating who takes responsibility ("I think that's definitely something that is on, let's say, on our desk in Amsterdam.") and how progress should be maintained ("So, hey, if you feel there is a constraint at this moment, just raise a flag and say we feel this is a constraint, but don't stop thinking about solutions on your side because you think there might be constraints on my side.").

This dynamic in the meeting is remarkable for two reasons. First of all, when people have to achieve things quickly (e.g., because of a short time to market), they may feel the need to get on with the task and to postpone discussions (Perlow \& Repenning, 2009). Furthermore, openly doubting the correctness, plausibility, or effectiveness of a solution, or pushing an agenda that "isn't yours" increases the risk of face-threats to other participants. However, conditionality (i.e., if-then constructions) and hedges ("Now, I'm brainstorming, so if I say nonsense, please correct me.") are used to avoid such face-threats. Secondly, this dynamic shows that there is room for uncertainty while it is the presumed enemy of commercial viability. Uncertainty about the extent of the technical possibilities, about whether something can be done or not, is not accounted to the academic partner. It seems to be accepted that there is simply no certain evaluation of results possible. Hence, the decision-making process about the next step to take can only be done in joint discussion.

\section{Motivation}

The safety to have an open discussion provided in the meeting confirms that when team members are more agreeable and extraverted in their communication style that they are more likely to exhibit a willingness and 


\section{Tread Carefully: Managing Identities and Expectations in High-Tech Industry- Academia Collaborations Els De Maeijer, Tom Van Hout, Mathieu Weggeman, and Ger Post}

eagerness to share knowledge (De Vries et al., 2006). To maintain such willingness, motivation plays an important role. In a concurring engineering process, small steps are made. This means that the bigger picture can disappear under pressure of technological uncertainty:

"There is a mismatch between what you would want, and what reasonably speaking is achievable. Of course, that is always the case in research, but that makes it harder to create enthusiasm with each other. Owing to the fact that we are dealing with such small blocks of work, we could lose some enthusiasm." (Project leader Phi)

Such conditions, described in research on creative work environments as dynamic "full speed", "go", and "breakneck" (Ekvall, 1996) create a need for leaders to energize their employees to be able to thrive. We distinguished the presence of "leading individuals" who apply a leadership discourse - combined with powerreducing strategies to assure that project members experience positive interaction with others - essential for staying motivated:

"Thank you for coming. I thought you had a very nice presentation. Now it has suddenly become clear what we want to look at. Nice, nice." (Partner from research centre in Phi at user meeting Phi)

"Maria spent four days fine-tuning results. We've seen them - they are really excellent. Spot on for us." (Industrial partner in Omicron at user meeting Omicron)

Leaders show openness to new ideas (as we have seen in the paragraph on joint alignment), value individual contribution to the work task, show confidence in those individuals, and provide constructive feedback (Amabile et al., 2004). When Eric, the industrial partner in Omicron, was asked for the motivation behind his contribution, he said: "I try to make contact, regardless of the direct or indirect relevance of the input for me." In a setting where getting results is not a nine-to-five business, and where "academics get stressed when they get asked 'how are things going?'”, one can imagine that confidence and approval for efforts, rather than for results can be essential to keep people motivated to contribute.

It has to be noted that this analysis seems hard to rhyme with analysis of the speaker-listener dynamic typical for a meeting set-up with presentations as a means to maintain the old hierarchical role division between industrials and academia. However, Eric is found to engage in status-reducing interactional strategies such as the use of self-deprecating humour (Angouri \& Marra, 2011) in combination with expressions of confirmation and appraisal:

Eric: "In fact, that's one of the reasons we hired Maria, to understand ourselves what's happening [Laughs]. No offense to the people we have already but it is - it should bring it on a higher level."

Hierarchy is implicit and accepted, but played down in the interaction to emphasize a sense of a team (Angouri \& Marra, 2011):

Eric: "This is what the alpha system looked like yesterday. [Shows slide of dismantled equipment] Any scientist would say that looks pretty good. You see some aluminum foil. Some measurement equipment. Some heating stuff. It's working."

Eric seems to mock or stereotype academia, but by showing the slide, he bridges the gap between science and industry; the dismantled tool is not a slick, commercial product, but resembles the scientific experiment on the scientist's desk. In the recognition of the image, Eric playfully triggers interest, which can increase individuals' capacity to think and act in the moment. (Dutton \& Heaphy, 2003). Positive emotions of joy and interest, in turn, facilitate more open, resourceful, and flexible cognitive processing as well as a more complex cognitive context, both which are essential for problem solving and creativity (Isen, 1999, 2004). It takes critical discourse awareness to be able to create such a positive, yet nuanced leader-member connection.

\section{Conclusion and Practical Implications}

The strictly managed set-up of the investigated meetings is grounded in the historical relationship between industry and academia. The set-up brings expectations about the roles and identities that partners take in relation to each other; academics are service providers who are allowed to provide value on the benevolence of the industrial. However, we found leading individuals with a sense of critical discourse awareness who are able to employ the institutional roles of the meeting to manage the dynamics of the collaboration by providing the attendees with a joint purpose, empowering them to think along, and motivating them to openly share pro- 


\section{Tread Carefully: Managing Identities and Expectations in High-Tech Industry- Academia Collaborations Els De Maeijer, Tom Van Hout, Mathieu Weggeman, and Ger Post}

gress. This results in a power shift: academics and industrials jointly (re)determine the course of the project and academics no longer solely bear the burden of technological uncertainty. This also means that academics are now free to pursue their own agenda. Both project leaders from Omicron and Phi can be found, for example, to ask for assurance that students have enough real-life material to work with or machine time available. Joint publications are pushed by the project leaders and, in both projects, this academic assertiveness can count on the explicit approval of the governmental intermediary during the meeting. Exemplary for the emancipation of academia is the project leader of Omicron, who explicitly limits the industrial partner advertising his product in the Omicron program meeting ("This feature is not on this machine, but in the future we will... [cut off by project leader]") as this does not match the "academic" setting of the meeting ("Yeah, yeah, yeah, so the future will be much nicer.")

Our findings suggest that the practice of industry-academia open innovation cannot be described as a simple dichotomy between industry and academia as much of the literature seems to suggest. On the one hand, there is still the tight grip of a relationship dominated by industrial instrumentalism. The acceleration of the market favours an instrumental, quick "thumbs-up, thumbs-down" approach, and meticulous time management allows for a smooth running of the collaborative process, but it does not necessarily stimulate open and fearless sharing of ideas. On the other hand, we have seen academia (re)claim the floor, facilitated by the presence of leading individuals. Their rhetorical choices, which we associated with a leadership discourse, provide a framework in which there is both the time and preparedness to discuss technological uncertainties. We argue that this relative ignorance allows for a process of serendipity to take place (MacDonald \& Piekkari, 2005). In the process of thinking along (Berends et al., 2011), ideas can emerge to further investigate unexpected applications or theoretical insights. If necessary, such discussions are followed up with joint realignment. This emancipatory process can benefit the knowledge-creation process.

Our research hence adds nuance to the idea that it is useful to have strong and senior industrials on board that know the company very well to understand its business needs, know how to access and assimilate external knowledge, and build partnerships with various partners (Vanhaverbeke et al., 2017). When we want to stimulate industry-academia open innovation, the presence of strong individuals, academic or industrial, who understand the discourse of joint knowledge creation with its inevitable relational dynamics grounded in presuppositions, fears, norms, and values of the participants is equally if not more important. We thus suggest a focus on the process rather than the conditions, on creation rather than assimilation, and on leadership rather than management, both in practice and in literature.

\section{Acknowledgements}

This article was developed from a paper presented at the ISPIM Innovation Conference in Stockholm, Sweden, June 17-20, 2018. ISPIM (ispim-innovation.com) the International Society for Professional Innovation Management - is a network of researchers, industrialists, consultants, and public bodies who share an interest in innovation management.

\section{About the Authors}

Els De Maeijer is a linguist and $\mathrm{PhD}$ Candidate at the Technical University of Eindhoven, Netherlands, where she is investigating open innovation collaborations between industry and academia. She challenges the idea that creating openness is just a matter of tweaking the conditions of collaborations. That is why she intensively studies the interaction between the collaborators themselves. Her work has been published in the Journal of Innovation Management, and she was the runner-up in the award for Best PhD Student Paper at the World Open Innovation Conference in 2017.

Tom Van Hout is Associate Professor and Academic Director of the Institute of Professional and Academic Communication at the University of Antwerp, Belgium. He holds a secondary appointment at Leiden University, the Netherlands. He studies professional and media communication to understand how expertise is performed, audiences are anticipated, and social events get represented. He is a founding member of two international research networks: Discourse in Organizations and NewsTalk\&Text. Recent publications include journal articles in Text \& Talk and IEEE Transactions in Professional Communication and book chapters in edited volumes published by Routledge and Oxford University Press.

Continued on next page... 


\section{Tread Carefully: Managing Identities and Expectations in High-Tech Industry- Academia Collaborations Els De Maeijer, Tom Van Hout, Mathieu Weggeman, and Ger Post}

\section{...continued from previous page.}

Mathieu Weggeman is Professor of Organization Management and specifically Innovation Management at the Faculty Industrial Engineering \& Innovation Sciences at the Technical University of Eindhoven, the Netherlands. He focuses on understanding and explaining innovation processes in technological, knowledgeintensive, and cultural organizations. He has a special interest in leadership and strategy in teams and organizations, and he supervises research on the motives of professionals to share knowledge. He is the author of the book Leading Professionals? Don't! A Continental European Perspective.

Ger Post is a Lector of Business Entrepreneurship at the Fontys University of Applied Science in Eindhoven, the Netherlands. He specializes and offers consultancy in entrepreneurship, personal competences, internal entrepreneurship, and entrepreneurship in networks. Ger has been involved in research aimed at changes in business, such as open innovation, clusters and alliances, facility sharing, and campus development. $\mathrm{He}$ is connected to the Fontys Center for Entrepreneurship and to the Centre of Expertise for High Tech Systems

\section{References}

Agogué, M., Yström, A., \& Le Masson, P. 2013. Rethinking the Role of Intermediaries as an Architect of Collective Exploration and Creation of Knowledge in Open Innovation. International Journal of Innovation Management, 17(2): 1-24. https://doi.org/10.1142/S1363919613500072

Agrawal, A., \& Cockburn, I. 2003. The Anchor Tenant Hypothesis: Exploring the Role of Large, Local, R\&D-Intensive Firms in Regional Innovation Systems. International Journal of Industrial Organization, 21(9): 1227-1253.

https://doi.org/10.1016/S0167-7187(03)00081-X

Amabile, T., Schatzel, E., Moneta, G., \& Kramer, S. 2004. Leader Behaviors and the Work Environment for Creativity: Perceived Leader Support. Leadership Quarterly, 15(1): 5-32.

https://doi.org/10.1016/j.leaqua.2003.12.003

Angouri, J., \& Marra, M. 2011. 'OK one last thing for today then': Constructing Identities in Corporate Meeting Talk. In J. Angouri \& M. Marra (Eds.), Constructing Identities at Work: 85-100. Basingstoke, UK: Palgrave Macmillan.

http://http:/doi.org/10.1057/9780230360051

Atwater, L., \& Carmeli, A. 2009. Leader-Member Exchange, Feelings of Energy, and Involvement in Creative Work. Leadership Quarterly, 20(3): 264-275.

https://doi.org/10.1016/j.leaqua.2007.07.009
Berends, H., Garud, R., Debackere, K., \& Weggeman, M. 2011. Thinking Along: A Process for Tapping into Knowledge Across Boundaries. International Journal of Technology Management, 53(1): 69-88.

https://doi.org/10.1504/IJTM.2011.037238

Bogers, M., Foss, N. J., \& Lyngsie, J. 2018. The "Human Side" of Open Innovation: The Role of Employee Diversity in Firm-Level Openness. Research Policy, 47(1): 218-231.

https://doi.org/10.1016/j.respol.2017.10.012

Briguglio, C. 2016. Gathering Linguistic Data from Multinational Companies. In G. M. Alessi \& G. Jacobs (Eds.), The Ins and Outs of Business and Professional Discourse Research: 81-101. Basingstoke, UK: Palgrave MacMillan.

Brose, H.-G. 2004. An Introduction Towards a Culture of NonSimultaneity. Time \& Society, 13(1): 5-26.

https://doi.org/10.1177/0961463X04040740

Chesbrough, H. 2006. Open Innovation. The New Imperative for Creating and Profiting from Technology. Boston, MA: Harvard Business School Press.

Costas, J., \& Grey, C. 2014. Bringing Secrecy into the Open: Towards a Theorization of the Social Processes of Organizational Secrecy. Organization Studies, 35(10): 1423-1447.

https://doi.org/10.1177/0170840613515470

Czarniawski, B. 2012. Organization Theory Meets Anthropology: A Story of an Encounter. Journal of Business Anthropology, 1(1): 118-140.

http://dx.doi.org/10.22439/jba.vli1.3549

De Maeijer, E., Van Hout, T., \& Weggeman, M. 2017. The Give and Take of Industry-Academia Partnerships. A Liminal Approach to Open Innovation. Paper presented at the 2017 World Open Innovation Conference. Berkeley, CA: The Garwood Center for Corporate Innovation.

De Maeijer, E., Van Hout, T., Weggeman, M., \& Post, G. 2017. Studying Open Innovation Collaboration between the High-Tech Industry and Science with Linguistic Ethnography-Battling over the Status of Knowledge in a Setting of Distrust. Journal of Innovation Management, 4(4): 8-31.

Djordjilovic, O. 2012. Displaying and Developing Team Identity in Workplace Meetings - A Multimodal Perspective. Discourse Studies, 14(1): 111-127.

https://doi.org/10.1177/1461445611427205

Drew, P., \& Heritage, J. 1992. Talk at Work: Interaction in Institutional Settings. Cambridge, UK: Cambridge University Press.

Dufresne, R., \& Offstein, E. 2008. On the Virtues of Secrecy in Organizations. Journal of Management Inquiry, 17(2): 102-106. https://doi.org/10.1177/1056492607313082

Dutton, J., \& Heaphy, E. 2003. Energize Your Workplace: How to Build and Sustain High-Quality Relationships at Work. San Francisco, CA: Jossey-Bass.

Eksner, H., \& Orellana, M. 2005. Liminality as Linguistic Process. Immigrant Youth and Experiences of Language in Germany and the United States. In J. Knoerre (Ed.), Childhood and Migration: 175-206. Bielefeld, Germany: Transcript Verlag.

Ekvall, G. 1996. Organizational Climate for Creativity and Innovation. European Journal of Work and Organizational Psychology, 5(1): 105-123. https://doi.org/10.1080/13594329608414845 


\section{Tread Carefully: Managing Identities and Expectations in High-Tech Industry- Academia Collaborations Els De Maeijer, Tom Van Hout, Mathieu Weggeman, and Ger Post}

Erickson, I. 2005. Network Dynamics and the Problem of Trust: A Structurationist Approach to Change in Interorganizational Collaboration. Stanford University Working Paper. Stanford, CA: Stanford University

Gargiulo, M., \& Benassi, M. 2000. Trapped in Your Own Net? Network Cohesion, Structural Holes, and the Adaptation of Social Capital. Organization Science, 11(2): 183-196.

https://doi.org/10.1287/orsc.11.2.183.12514

Garud, R., Gehman, J., \& Giuliani, A. P. 2014. Contextualizing Entrepreneurial Innovation: A Narrative Perspective. Research Policy, 43(7): 1177-1188. https://doi.org/10.1016/j.respol.2014.04.015

Goffman, E. 1967. Interaction Ritual: Essays on Face-to-face Behaviour. New York: Pantheon Books.

Goia, D. 2013. Organizational Identity Formation and Change. The Academy of Management Annals, 7(1): 123-192. https://doi.org/10.1080/19416520.2013.762225

Grant, D., Lawrence, T. B., \& Grant, D. 2005. Discourse and Collaboration: The Role of Conversations and Collective Identity. Academy of Management Review, 30(1): 58-77. https://doi.org/10.5465/amr.2005.15281426

Hassan, R. 2003. Network Time and the New Knowledge Epoch. Time \& Society, 12(2/3): 225-241.

https://doi.org/10.1177/0961463X030122004

Holmes, J., \& Stubbe, M. 2003. Power and Politeness in the Workplace. London: Pearson Education.

Isen, A. 1999. Positive Affect and Creativity. In S. W. Russ (Ed.), Affect, Creative Experience, and Psychological Adjustment: 3-17. Philadelphia, PA: Brunner/Mazel.

Isen, A. 2004. Some Perspectives on Positive Feelings and Emotions: Positive Affect Facilitates Thinking and Problem Solving. In A. S. R. Manstead, N. Frijda, \& A. Fischer (Eds.), Studies in Emotion and Social Interaction. Feelings and Emotions: The Amsterdam Symposium: 263-281. Cambridge, UK: Cambridge University Press. https://doi.org/10.1017/CBO9780511806582.016

Koller, V. 2017. Language Awareness and Language Workers. Language Awareness, 27(1-2): 1-17.

https://doi.org/10.1080/09658416.2017.1406491

Kunda, G. 1992. Engineering Culture. Philadephia, PA: Temple University Press.

Langley, A., Smallman, C., Tsoukas, H., \& Van De Ven, A. H. 2013. Process Studies of Change in Organization and Management: Unveiling Temporality, Activity and Flow. Academy of Management Journal, 56(1): 1-13.

https://doi.org/10.5465/amj.2013.4001

Lehtinen, E., \& Pälli, P. 2011. Conversational Use of Genres in Managerial Meetings. Scandinavian Journal of Management, 27(3): 287-96.

https://doi.org/10.1016/j.scaman.2011.06.003

Lerner, G. 1987. Collaborative Turn Sequences: Sentence Construction and Social Action. Irvine, CA: University of California.

Levinson, S. 1992. Activity Types and Language. In P. Drew \& J. Heritage (Eds.), Talk at Work. Interaction in Institutional Settings: 66-100. New York: Cambridge University Press.

Lofland, J., \& Lofland, L. H. 1995. Analyzing Social Settings: A Guide to Qualitative Observation and Analysis. Belmont, CA: Wadsworth.
MacDonald, S., \& Piekkari, R. 2005. Out of Control: Personal Networks in European Collaboration. R\&D Management, 35(4): 441-453. https://doi.org/10.1111/j.1467-9310.2005.00400.x

McCray, W. P. 2005. Will Small Be Beautiful? Making Policies for Our Nanotech Future. History and Technology, 21(2): 177-203. https://doi.org/10.1080/07341510500103735

McInnis, C. 2001. Signs of Disengagement: The Changing Undergraduate Experience in Australian Universities. Melbourne, Australia: University of Melbourne, Faculty of Education.

Merriam Webster. 2018. Present. Merriam Webster Dictionary. Accessed April 5, 2018:

https://www.merriam-webster.com/dictionary/present

Moore, W. 1962. The Conduct of the Corporation. New York: Random House.

Nielsen, M. F. 2010. Positioning - Middle Managers' Communicative Work on Leadership Space and Leadership Legitimacy. Copenhagen: Samfundslitteratur.

Nielsen, M. F. 2013. "Stepping Stones" in Opening and Closing Department Meetings. Journal of Business Communication, 50(1): 34-67.

https://doi.org/10.1177/0021943612465182

Norlyk, B. 2012. Genres at the Top: Leadership, Management and Genre. In P. Gillaerts, E. de Groot, S. Dieltjens, P. Heynderickx, \& G. Jacobs, Researching Discourse in Business Genres. Cases and Corpora: 97-112. Bern, Switzerland: Peter Lang.

Perkmann, M., \& Walsh, K. 2007. University-Industry Relationships and Open Innovation: Towards a Research Agenda. International Journal of Management Reviews, 9(4): 259-280.

https://doi.org/10.1111/j.1468-2370.2007.00225.x

Perkmann, M., Neely, A., \& Walsh, K. 2011. How Should Firms Evaluate Success in University-Industry Alliances? A Performance Measurement System. R\&D Management, 41(2): 202-216. https://doi.org/10.1111/j.1467-9310.2011.00637.x

Perlow, L. A., \& Repenning, N. P. 2009. The Dynamics of Silencing Conflict. Research in Organizational Behavior, 29: 195-223. https://doi.org/10.1016/j.riob.2009.06.007

Potter, J., \& Wetherell, M. 1987. Discourse and Social psychology: Beyond Attitudes and Behaviour. London: Sage.

Schegloff, E. A., \& Sacks, H. 1973. Opening up Closings. Journal of the International Association for Semiotic Studies, 8(4): 289-327. http://dx.doi.org/10.1515/semi.1973.8.4.289

Schiller, D. 1999. Digital Capitalism. Cambridge, MA: MIT Press.

Schmoch, U. 1999. Interaction of Universities and Industrial Enterprises in Germany and the United States - A Comparison. Industry and Innovation, 6(1): 51-68.

https://doi.org/10.1080/13662719900000004

Shaw, S., Copland, F., \& Snell, J. 2015. An Introduction to Linguistic Ethnography: Interdisciplinary Explorations. In F. Copland, S. Shaw, \& J. Snell (Eds.), Linguistic Ethnography: 1-13. London: Palgrave MacMillan.

Simard, C., \& West, J. 2006. Knowledge Networks and the Geographic Locus of Innovation. In H. Chesbrough, W. Vanhaverbeke, \& J. West (Eds.), Open Innovation. Researching a New Paradigm: 220-240. Oxford, UK: Oxford University Press. 


\section{Tread Carefully: Managing Identities and Expectations in High-Tech Industry- Academia Collaborations Els De Maeijer, Tom Van Hout, Mathieu Weggeman, and Ger Post}

Spencer-Oaty, H. 2009. Face, Identity and Interactional Goals. In F. Bargiela-Chiappini \& M. Haugh (Eds.), Face, Communication and Social Interaction: 137-154. London: Equinox Publishing Ltd.

Urban, G., \& Koh, K.-N. 2013. Ethnographic Research on Modern Business Corporations. The Annual Review of Anthropology, 42: 139-158.

https://doi.org/10.1146/annurev-anthro-092412-155506

Urciuoli, B., \& LaDousa, C. 2013. Language Management/Labor. Annual Review of Anthropology, 42: 175-190.

https://doi.org/10.1146/annurev-anthro-092412-155524

Vanhaverbeke, W., Cheng, J., \& Chesbrough, H. 2017, February 20. A Profile of Open Innovation Managers in Multinational Companies. The University of Hasselt, the University of California Berkeley, ESADE Business School, and the National University of Singapore.

Vanhaverbeke, W., Chesbrough, H., \& West, J. 2014. Surfing the New Wave of Open Innovation Research. In H. Chesbrough, W. Vanhaverbeke, \& J. West (Eds.), New Frontiers in Open Innovation: 281-294. New York: Oxford University Press.

Villani, D., Cipresso, P., Gaggioli, A., \& Riva, G. 2016. Integrating Technology in Positive Psychology Practice. Hershey, PA: Information Science Reference, IGI Global.

Weninger, C., \& Kan, K. H.-Y. 2013. (Critical) Language Awareness in Business Communication. English for Specific Purposes, 32(2): 59-71.

https://doi.org/10.1016/j.esp.2012.09.002

Zand, D. E. 1972. Trust and Managerial Problem Solving. Administrative Science Quarterly,17(2): 229-239.

https://doi.org/10.2307/2393957

Citation: De Maeijer, E., Van Hout, T., Weggeman, M., \& Post, G. 2018. Tread Carefully: Managing Identities and

Expectations in High-Tech Industry-Academia

Collaborations. Technology Innovation Management

Review, 8(10): 29-43.

http://doi.org/10.22215/timreview/1191

Keywords: open innovation, industry-academia,

interaction, critical discourse awareness, leadership 


\section{Academic Affiliations and Funding Acknowledgements}

Canadà
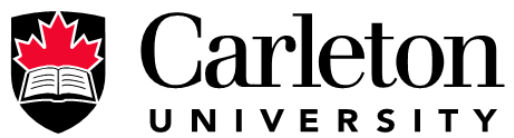

U N I V E R S I T Y

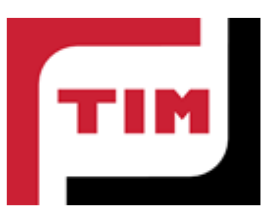

The Federal Economic Development Agency for Southern Ontario (FedDev Ontario; feddevontario.gc.ca) is part of the Innovation, Science and Economic Development portfolio and one of six regional development agencies, each of which helps to address key economic challenges by providing regionallytailored programs, services, knowledge and expertise.

- The TIM Review receives partial funding from FedDev Ontario's Investing in Regional Diversification initiative.

Technology Innovation Management (TIM; timprogram.ca) is an international master's level program at Carleton University in Ottawa, Canada. It leads to a Master of Applied Science (M.A.Sc.) degree, a Master of Engineering (M.Eng.) degree, or a Master of Entrepreneurship (M.Ent.) degree. The objective of this program is to train aspiring entrepreneurs on creating wealth at the early stages of company or opportunity lifecycles.

- The TIM Review is published in association with and receives partial funding from the TIM program. 